\title{
SIRT5 is important for bacterial infection by regulating insulin secretion and glucose homeostasis
}

\section{Dear Editor,}

Recent studies indicate that cellular metabolism plays a key role in supporting immune cell development, maintenance and function (Norata et al., 2015). For example, sensing of microbial ligands by macrophages triggers increased glucose metabolism, which delivers energy to support antimicrobial inflammation and the production of cytokines. This effect further enhances the generation of mitochondrial reactive oxygen species (ROS) to fight infections. Tucey et al. show that maintaining host glucose homeostasis is important to prevent life-threatening fungal infection (Tucey et al., 2018). This phenomenon emerges as a bedrock of the emerging concept of how metabolism and immunity are integrated based on bioenergy requirements.

Sirtuins contribute to dynamic shifts in immunity, metabolism, and bioenergetics during inflammation (Vachharajani et al., 2016). Therefore, targeting Sirtuins is likely to deliver new opportunities for manipulating immunometabolism as an anti-inflammatory strategy. However, better understanding of Sirtuin biology and its role in regulation of inflammation is in its infancy. SIRT1 acts as a key control point for regulating metabolism and inflammatory outputs from T cells (Liu et al., 2012). In our previous work, we demonstrated that SIRT5 plays an important role in preventing dextran sulfate sodium (DSS)-induced colitis by regulating glycolysis in macrophages (Wang et al., 2017). Inflammation in DSS-induced colitis is not of infectious origin. We would like to know the function of SIRT5 in infection-induced inflammation and host defense.

To study the role of SIRT5 in infection response, we treated littermate wild-type (WT) and Sirt5-deficient $\left(\right.$ Sirt $5^{-1-}$ ) mice with lipopolysaccharide (LPS). When Sirt5 $5^{-1}$ mice were treated with LPS for $3 \mathrm{~h}$, the level of blood glucose decreased and the level of serum insulin increased significantly (Fig. 1A and 1B), accompanied with increased concentration of circulating IL-1 $\beta$ (Fig. 1C). Peritoneal macrophages (PMs) from Sirt5 ${ }^{-1-}$ mice treated with LPS also expressed higher level of $I I-1 \beta$ mRNA and secreted more IL$1 \beta$ (Fig. S1A and S1B). These results indicated that SIRT5 has a potential role in regulating glucose homeostasis and
Sirt5 deficiency boosts IL-1 $\beta$ production in inflammatory response.

Then, we wanted to know the source of the elevated IL$1 \beta$. The gating strategies of flow cytometry for immune cells have been shown in Fig. S1C. We found that the $\mathrm{F} 4 / 80^{+}$/ $\mathrm{CD}_{11} \mathrm{~b}^{+}$macrophages accounted for the largest proportion of the immune cells isolated from peritoneal cavity of Sirt $5^{-1-}$ mice treated with LPS (Fig. S1D), which is consistent with a previous interesting report (Dror et al., 2017). Depletion of the peritoneal macrophages by intraperitoneal injection of clodronate liposomes (Fig. S1E) eliminated the effect induced by LPS treatment in Sirt5 ${ }^{-1-}$ mice. The blood glucose, circulating insulin and IL-1 $\beta$ level in LPS-treated Sirt5 $5^{-1}$ mice showed no significant difference with that in WT mice (Fig. 1D-F). Therefore, LPS induced elevation of IL-1 $\beta$ in Sirt $5^{1-}$ mice is mainly from the intraperitoneal macrophages.

The NLRP3 inflammasome was shown to be a pivotal player in sepsis and the activation of the NLRP3 inflammasome cause IL-1 $\beta$ and IL-18 production (Ting et al., 2008). So, we assumed that the inflammasome activation might be enhanced by LPS treatment in Sirt5 ${ }^{1-}$ macrophages. In Sirt $5^{-1-}$ bone marrow derived macrophages (BMDMs) cells, treatment with LPS did not change the level of SIRT5 protein, while significantly upregulated mRNAs level of NRLP3 and IL-1 $\beta$, compared to the WT counterparts (Fig. S2A-C). With LPS priming, ATP promoted the cleavage of caspase 1 and the maturation of IL-1 $\beta$. The result showed both signal 1 and signal 2 of the NLRP3 inflammasome were activated (Fig. 1G) (Hao et al., 2017). The IL-1 $\beta$ released into BMDMs supernatant was confirmed by ELISA (Fig. 11). While the caspase-1 inhibitor ZYVAD abolished IL-1 $\beta$ release in both WT and Sirt5 $5^{-1-}$ BMDMs (Fig. $1 \mathrm{G}$ and $1 \mathrm{H}$ ). Furthermore, we investigated the mechanisms involved in inflammasome activation. ROS are pivotal for inflammasome activation (Schroder and Tschopp, 2010). Treatment with LPS and ATP increased ROS production in Sirt5 $5^{-1-}$ macrophages when compared to WT macrophages, and this was inhibited by ROS inhibitor N-acetyl-cysteine (NAC) and NAPDH oxidase inhibitor diphenyleneiodonium (DPI) (Fig. 1I). Inhibition of ROS production also suppressed IL-1 $\beta$ release as assessed by ELISA (Fig. 1J). Together, these findings reveal that LPS- 
A

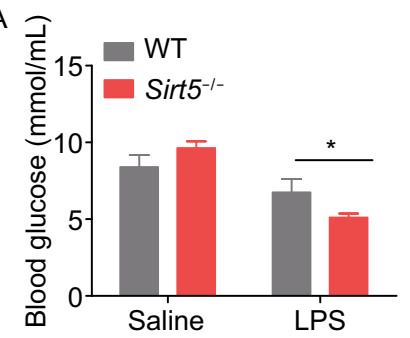

D

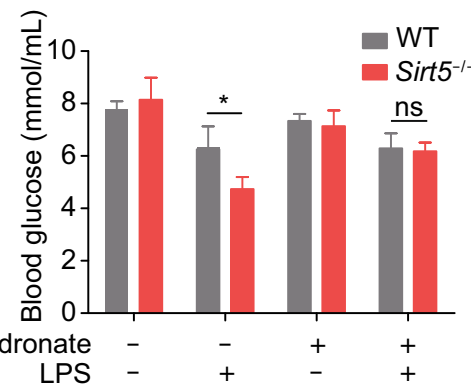

G

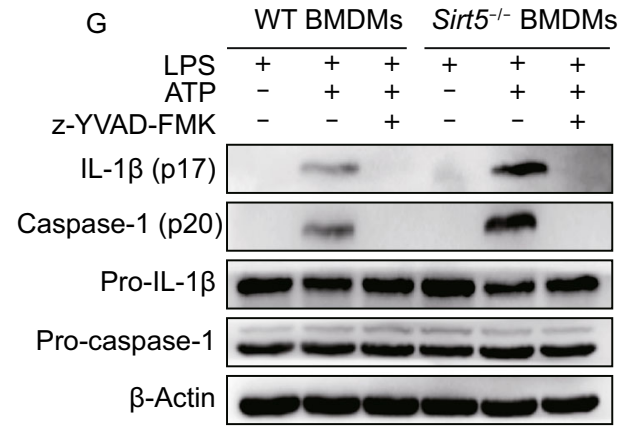

J BMDMs supernatant

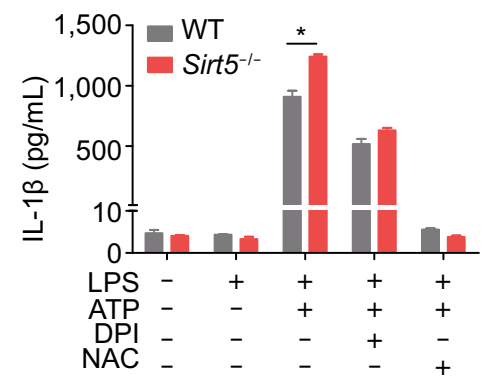

m

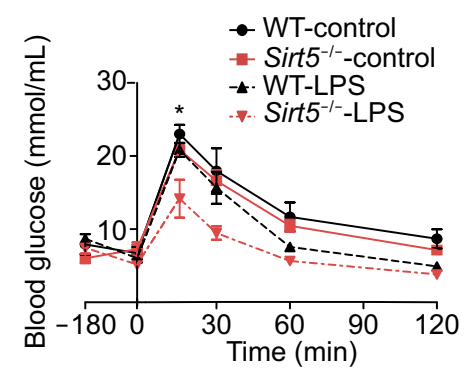

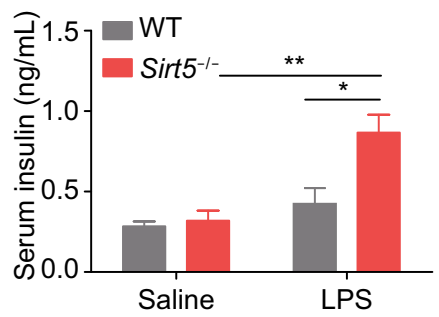

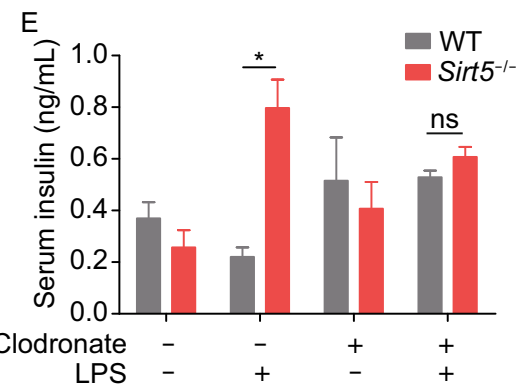

$\mathrm{H}$$$
\text { = }
$$

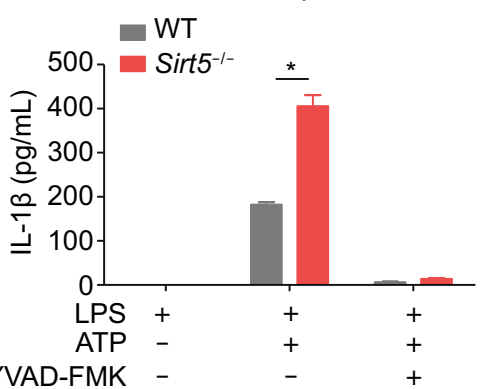

$\mathrm{K}$

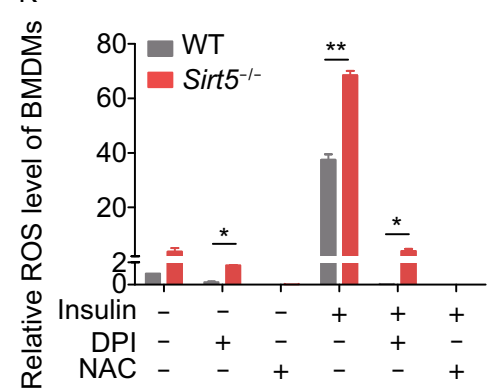

$\mathrm{N}$

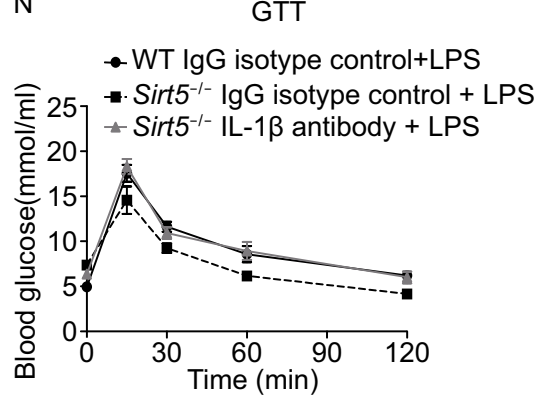

C
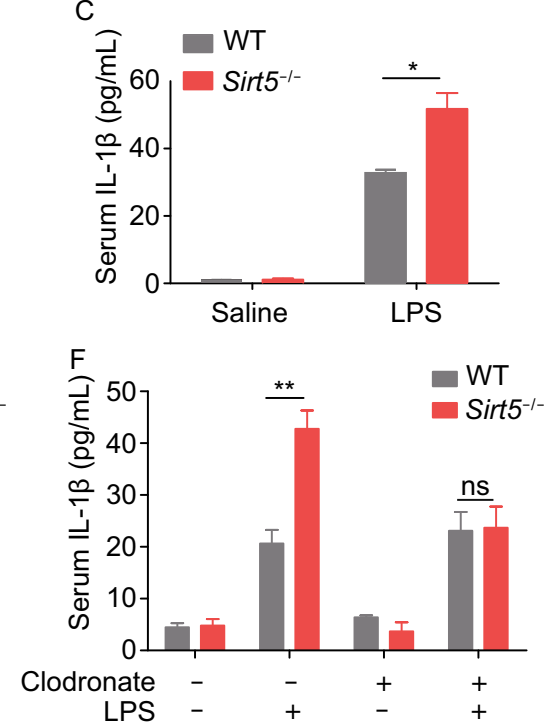

I

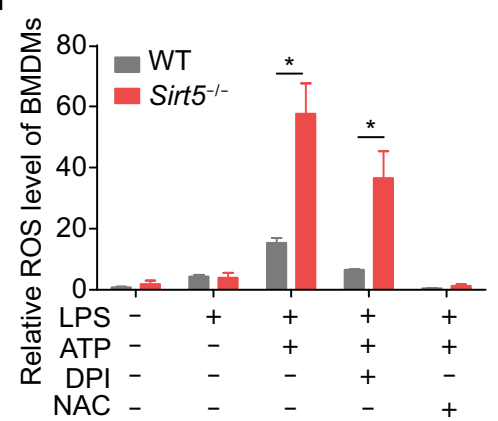

L

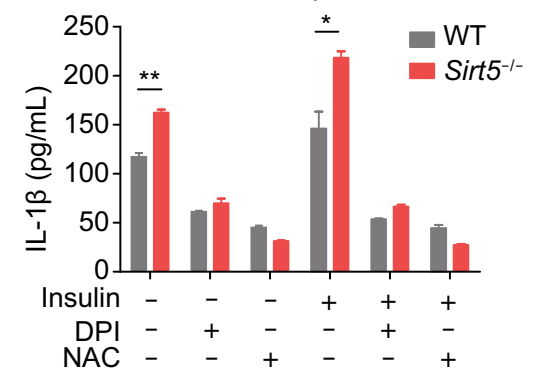

O

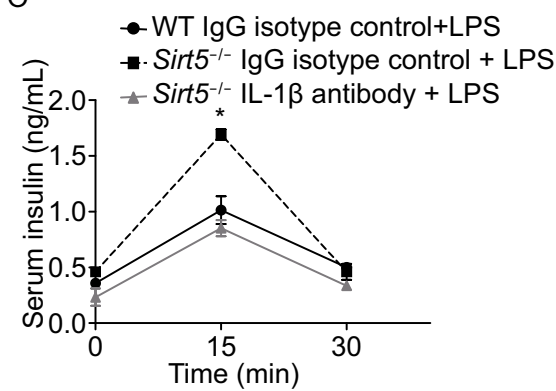


4 Figure 1. Macrophage-derived IL-1 $\beta$ stimulates insulin in Sirt5 $5^{-1-}$ mice, and both synergistically regulate glucose homeostasis. (A) Blood glucose, (B) serum insulin and (C) circulating IL-1 $\beta$ were determined before and after intraperitoneal injection of LPS for $3 \mathrm{~h}(1 \mathrm{mg} / \mathrm{kg})$ into wild-type (WT) mice and Sirt5 ${ }^{-1-}$ mice ( $n=3-7 /$ group). (D) Blood glucose level, (E) serum insulin and $(F)$ circulating IL-1 $\beta$ were determined before and after LPS stimulation upon intraperitoneal injection of $10 \mathrm{~mL} / \mathrm{kg}$ clodronate or PBS liposomes ( $n=3 /$ group). (G) Immunoblotting for IL-1 $\beta$ (p17), activated caspase-1 (p20) in supernatant (Sup), and pro-IL-1 $\beta$, pro-caspase-1, $\beta$-actin in cell lysates (Lys) in the absence or presence of the caspase-1 inhibitor z-YVAD-FMK $(10 \mu \mathrm{mol} / \mathrm{L}, 1 \mathrm{~h})$. (H) ELISA for IL-1 $\beta$ in supernatant from LPS-primed BMDMs $(100 \mathrm{ng} / \mathrm{mL}, 5.5 \mathrm{~h})$ in the absence or presence of the caspase-1 inhibitor Z-YVAD-FMK (10 $\mu \mathrm{mol} / \mathrm{L}, 1 \mathrm{~h})$. (I) ROS and (J) IL-1 $\beta$ production were determined in resting or LPS-primed BMDMs stimulated with or without ROS inhibitors N-acetyl-cysteine (NAC, $25 \mathrm{mmol} / \mathrm{L}, 1 \mathrm{~h}$ ) or NAPDH oxidase inhibitor diphenyleneiodonium (DPI, 25 $\mu \mathrm{mol} / \mathrm{L}, 1 \mathrm{~h}$ ). (K) ROS and (L) IL-1 $\beta$ production in LPS-primed BMDMs stimulated with or without insulin $(1 \mu \mathrm{g} / \mathrm{mL}, 5 \mathrm{~min})$, NAC $(25 \mathrm{mmol} / \mathrm{L}, 1 \mathrm{~h})$ or DPI $(25 \mu \mathrm{mol} / \mathrm{L}, 1 \mathrm{~h})$. (M) Concentration of blood glucose during an intraperitoneal GTT in WT or Sirt5 ${ }^{-1-}$ mice after injection of saline (control) or LPS (1 mg/kg) for 180 $\min (n=3 /$ group); 0 min indicates GTT start time throughout GTT analyses. (N) Concentration of blood glucose, and (O) circulating insulin (G) during an intraperitoneal GTT in mice 180 min after injection of LPS (1 $\mathrm{mg} / \mathrm{kg}$ ) with $\mathrm{lgG}$ isotype control (100 $\mu \mathrm{g}$ each) or IL-1 $\beta$ neutralizing antibody (100 $\mu \mathrm{g}$ each) $(n=$ 3/group). Data represent mean \pm SEM, ${ }^{*} P<0.05$, ${ }^{* *} P<0.01$.

induced IL-1 $\beta$ secretion in Sirt5 $5^{-1-}$ BMDMs depended on NLRP3 inflammasome activation and ROS production.

Published in vitro studies (Hajmrle et al., 2016) have demonstrated that IL-1 $\beta$ enhance the glucose-stimulated secretion of insulin from islets. Meanwhile, resident macrophages isolated from various tissues express insulin receptor (InsR) (Dror et al., 2017). Increased InsR expression in the macrophages of diet-induced obesity (DIO) mice has been reported and insulin reversely reinforced the inflammatory state of macrophages. Although we did not find upregulation of InsR in Sirt5 ${ }^{-1-}$ BMDMs than WT counterparts (data not shown), we did observe that insulin treatment significantly increased the production of IL-1 $\beta$ in M1 BMDMs derived from Sirt5 ${ }^{-1-}$ mouse (Fig. S3A). Also, insulin treatment increased the production of ROS and IL- $1 \beta$ in Sirt5 $5^{-1-}$ BMDMs primed with LPS. Both ROS and IL- $1 \beta$ were suppressed by NAC or DPI (Fig. 1K-L). PI3K-AKT and MAPK (JNK, p38 and ERK) signaling pathway have been shown to have a close relationship with insulin signal transduction. Then we measured these pathways. The extent of insulininduced phosphorylation of the kinase AKT was greater in Sirt5 $5^{-1-}$ BMDMs than WT BMDMs (Fig. S3B, lanes 4 and 8). We noticed that the single insulin treatment did not induce p-AKT (Fig. S3B, lanes 1 and 2), which may result from the type of macrophage. According to the work of Dror et al, insulin has activity in M1 macrophages but not in naive or M2 macrophages (Dror et al., 2017). Insulin also enhanced higher phosphorylation of $\mathrm{JNK}$ in Sirt5 ${ }^{-1-}$ BMDMs than WT BMDMs (Fig. S3B, lanes 4 and 8). Together, these findings indicated that increased $\mathrm{IL}-1 \beta$ concentrations enhanced insulin secretion. Secreted insulin may bind to InsR on macrophages, leading to enhanced AKT and JNK phosphorylation, ROS production, as well as IL-1 $\beta$ production.

We also treated WT or Sirt5 $5^{-1-}$ mice with LPS, followed by an intraperitoneal glucose tolerance test (GTT) and insulin tolerance test (ITT). Injection of LPS improved glucose tolerance in Sirt5 $5^{-1-}$ mice (Figs. $1 \mathrm{M}$ and S4A), but had no effect on insulin sensitivity (Fig. S4B and S4C). Sirt5 $5^{-1}$ mice treated with $\mathrm{IL}-1 \beta$ neutralizing antibody exhibited an impaired glucose tolerance during GTT when compared with those receiving IgG (Figs. $1 \mathrm{~N}$ and S4D). Also, the level of serum insulin in Sirt5 ${ }^{-/-}$mice administered by IL-1 $\beta$ neutralizing antibody decreased significantly during GTT, when compared with those receiving IgG (Fig. 10). Specific immunostaining of mouse pancreatic tissue sections with insulin antibody confirmed that blocking IL-1 $\beta$ can suppress insulin secretion (Fig. S4E). In order to investigate the pathways mediating insulin secretion in islet $\beta$-cell, we further isolated islets from WT or Sirt $5^{1-}$ mice and evaluated the ex vivo impact of SIRT5 on insulin secretion. Sirt5 $5^{-1-}$ led to enhanced AKT phosphorylation in islets (Fig. S4F). IL-1ß or LPS-stimulated insulin secretion was markedly increased in Sirt5 ${ }^{-1-}$ islets (Fig. S4G and S4H). Both basal and glucose-stimulated insulin secretion were significantly increased in Sirt5 ${ }^{-/}$islets (Fig. S4I). These results indicated that during the inflammatory response, Sirt 5 deficiency leads to IL-1 $\beta$ production and insulin secretion, which regulates glucose homeostasis. There was a positive feedback between macrophage and $\beta$ cell. Previous finding also showed that SIRT6 was essential for proper glucose homeostasis (Zhong et al., 2010).

To better understand the role of macrophage SIRT5 in regulating glucose homeostasis, we deleted Sirt5 in macrophages by transplanting WT recipient mice with WT $(\mathrm{WT} \rightarrow \mathrm{WT})$ or Sirt5 ${ }^{-1-}\left(\mathrm{Sirt5}^{-1-} \rightarrow \mathrm{WT}\right)$ bone marrow cell. Upon reconstitution, Sirt $5^{-1-} \rightarrow \mathrm{WT}$ chimeras displayed decreased level of blood glucose, increased level of serum insulin and IL-1 $\beta$, compared with those of WT $\rightarrow$ WT (Fig. S5A-C). The assay of GTT and ITT showed same results with Fig.1M and Fig.S4B, although it did not reach statistical significance (Fig. S5D and S5E).

In order to characterize the effect of SIRT5 on glucose homeostasis in infection, we challenged the mice with Salmonella typhimurium (strain SL1344). The blood glucose of WT and Sirt5 $5^{-1-}$ mice with S. typhimurium show a trend of decline during the infection; when compared to WT mice, Sirt5 $5^{-1-}$ mice had a lower level of blood glucose at $12 \mathrm{~h}$ post bacterial infection (Fig. 2A). Accordingly, Sirt5 ${ }^{-1-}$ mice had significantly higher level of serum insulin at $12 \mathrm{~h}$ and $24 \mathrm{~h}$ post infection than WT mice (Fig. 2B). The level of IL-1 $\beta$ in 

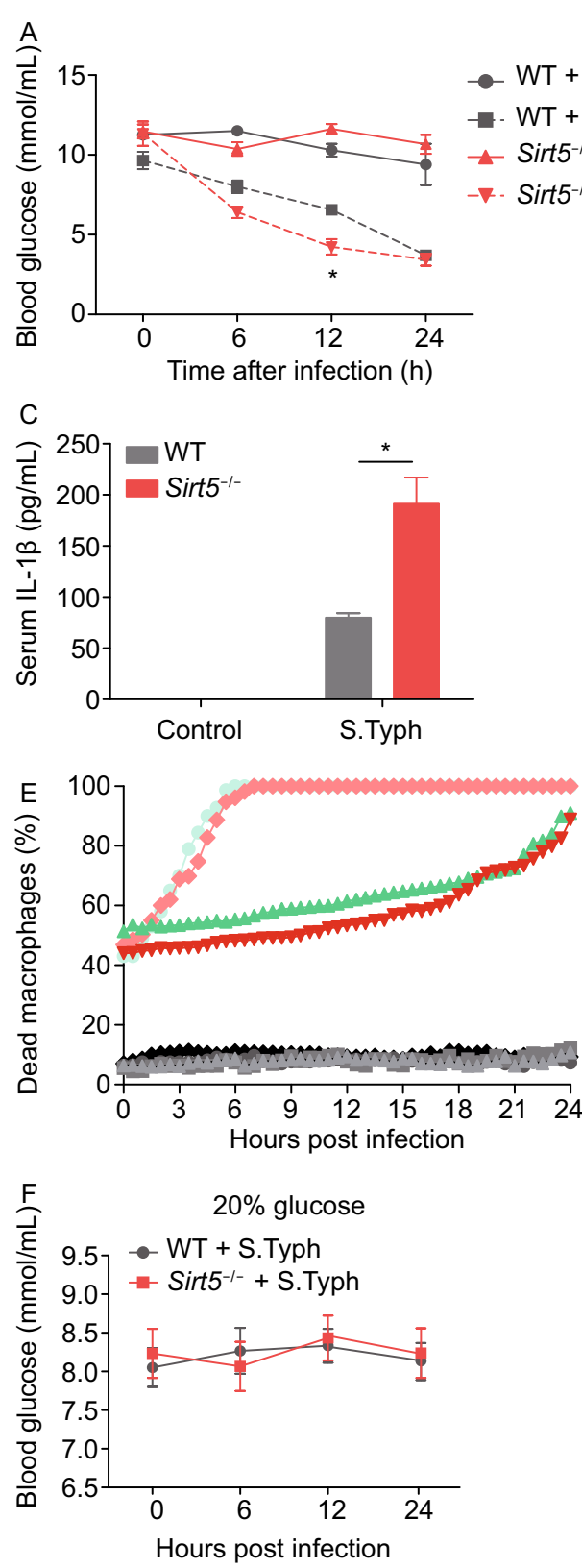

$\mathrm{H}$

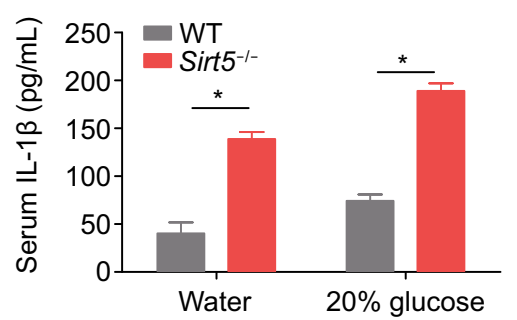

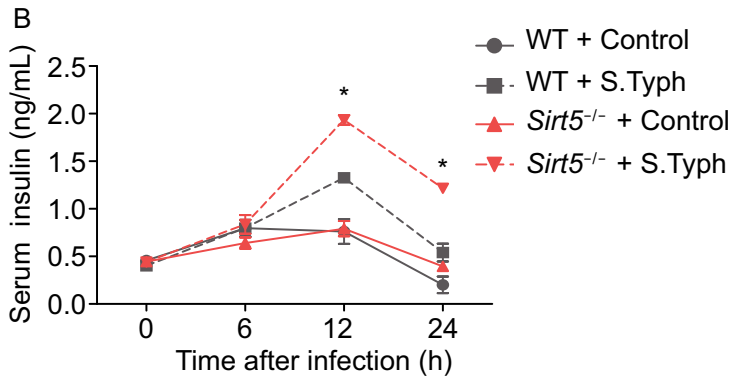

D

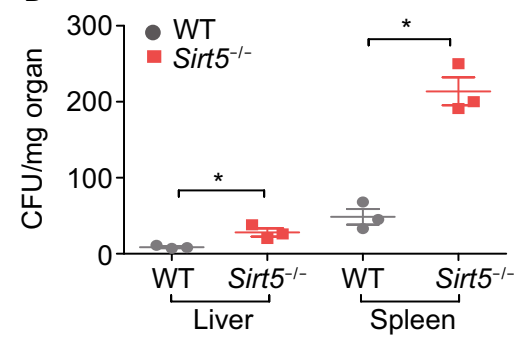

$\mathrm{WT}+5 \mathrm{mmol} / \mathrm{L}$ glucose $+\mathrm{MOI}=1$

$-\mathrm{KO}+5 \mathrm{mmol} / \mathrm{L}$ glucose $+\mathrm{MOI}=1$

$-\mathrm{WT}+25 \mathrm{mmol} / \mathrm{L}$ glucose $+\mathrm{MOI}=1$

$\rightarrow \mathrm{KO}+25 \mathrm{mmol} / \mathrm{L}$ glucose $+\mathrm{MOI}=1$

$-\mathrm{WT}+5 \mathrm{mmol} / \mathrm{L}$ glucose

$-W T+25 \mathrm{mmol} / \mathrm{L}$ glucose

$-\mathrm{KO}+5 \mathrm{mmol} / \mathrm{L}$ glucose

$-\mathrm{KO}+25 \mathrm{mmol} / \mathrm{L}$ alucose
G

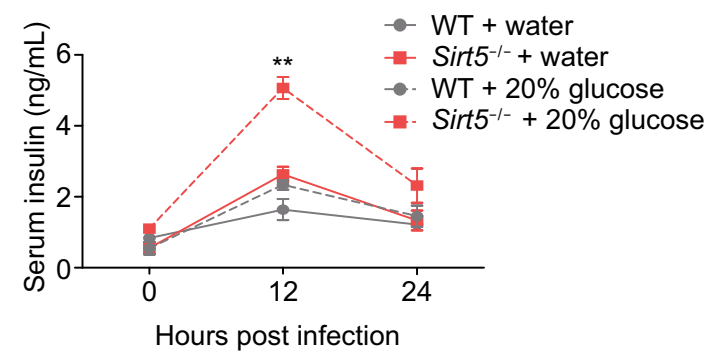

I

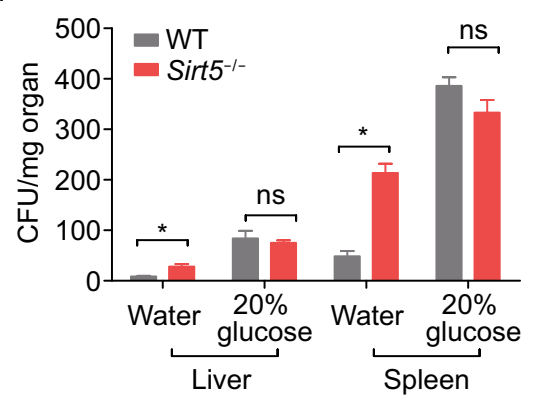


4 Figure 2. Sirt5 deficiency promotes bacterial dissemination in Salmonella typhimurium infection model, and glucose supplementation improves host inflammatory response. ( $A$ and $B$ ) Concentration of blood glucose $(A)$ and insulin (B) after a single intraperitoneal injection of $S$. typhimurium SL1344 strain ( $1 \times 10^{6} \mathrm{CFU} /$ mouse $)$ for $6 \mathrm{~h}, 12 \mathrm{~h}$ and $24 \mathrm{~h}$. (C) Mice were infected as in (A), and sacrificed $24 \mathrm{~h}$ post infection. IL-1 $\beta$ in serum was measured by ELISA. (D) Livers and spleens were extracted after $24 \mathrm{~h}$ infection and the $\mathrm{CFU} / \mathrm{mg}$ organ were determined ( $n=3 /$ group). (E) Comparison of WT and $\mathrm{Sirt}^{-1-}$ macrophage cell death in medium containing different concentrations of glucose. S. typhimurium was used to infect macrophages at $1 \mathrm{MOI}$. (F) Blood glucose levels over time in S. typhimurium infected mice fed with $20 \%$ glucose in the drinking water $\left(1 \times 10^{6} \mathrm{CFU} /\right.$ mouse i.p., $n=3 /$ group $)$. (G) Concentration of serum insulin over time in S. typhimurium infected mice fed with drinking water or $20 \%$ glucose in the drinking water $\left(1 \times 10^{6} \mathrm{CFU} /\right.$ mouse i.p., $n=3 /$ group $)$. (H) Mice were infected as in $(F)$, and sacrificed $24 \mathrm{~h}$ post infection. IL-1 $\beta$ in serum was measured by ELISA. (I) Livers and spleens were extracted after $24 \mathrm{~h}$ infection and the CFU/mg organ were determined ( $n=3$ /group). Data represent mean \pm SEM, ${ }^{*} P<$ $0.05,{ }^{* *} P<0.01$.

serum and supernatant of PMs from infected Sirt5 ${ }^{-1-}$ mice increased much more than WT mice as expected (Figs. 2C and S6A). Also, II-1 $\beta$ mRNA expression increased in PMs, liver and spleen at $24 \mathrm{~h}$ post infection and the increase was higher in Sirt5 ${ }^{-1-}$ mice than WT mice (Fig. S6B-D). In order to measure bacterial dissemination, mice were sacrificed at $24 \mathrm{~h}$ post infection with $S$. typhimurium i.p.; livers and spleens were extracted and the bacterial load determined by colony-forming units (CFUs)/mg. The bacterial load of livers and spleens from infected Sirt5 ${ }^{-1-}$ mice were much higher than that in WT mice (Fig. 2D). Together, these data demonstrate that SIRT5 is important in maintaining glucose homeostasis for controlling inflammation during bacterial challenge.

We next asked if maintaining glucose homeostasis in Sirt5 - mice can improve the outcomes of bacterial infection. In vitro analysis showed that supplementation with high glucose (25 $\mathrm{mmol} / \mathrm{L}$ ) medium delayed macrophage cell death in both WT and Sirt5 ${ }^{-1-}$ BMDMs infected with bacteria (Fig. 2E). Bacteria seem to preferentially use glucose compared with fungi (Tucey et al., 2018). Upon glucose supplementation, bacteria proliferate very rapidly. The media in the in vitro experiment presented in Fig. 2E became yellow and turbid very fast, which might interfere with our data, but we can still observe the BMDMs cell death in Sirt $5^{-1-}$ were slightly decreased from $0 \mathrm{~h}$ to $18 \mathrm{~h}$ when compared with the WT counterparts.

This implies the glucose is essential for macrophage to mount effective anti-bacterial response. In an in vivo study, the blood glucose of mice fed with $20 \%$ glucose maintained higher levels of glucose during the infection (Fig. 2F). The serum insulin in infected Sirt5 $5^{-1-}$ mice fed with glucose was significantly increased (Fig. 2G). We observed that serum levels of IL-1 $\beta$ and supernatant from $P M s$ were much higher after glucose feeding, especially in Sirt $5^{-1-}$ mice (Figs. $2 \mathrm{H}$ and S6E). $I /-1 \beta$ mRNA expression increased in PMs, liver and spleen in glucose-fed Sirt5 ${ }^{-1-}$ mice (Fig. S6F-H). When the mice were fed with drinking water, the liver and spleen bacterial burden were higher in Sirt5 ${ }^{-1-}$ mice than that in WT mice (Fig. 2D). We observed that glucose-feeding significantly increased liver and spleen bacterial burden in both Sirt5 $5^{-1}$ and WT mice, compared with the group fed drinking water, the increased portions of Sirt5 $5^{-1-}$ group was smaller than that in WT group (Fig. 2l). This indicates that administration of glucose rescues the infection-induced hypoglycemia, and higher glucose promotes host inflammatory response against bacterial infection.

We appreciate that Heinon et al. have recently reported that Sirt5 deficiency does not compromise the response to bacterial infection (Heinonen et al., 2018). We used different background mice and bacterial strains from them. Maybe this is where the different results come from.

Accumulated evidence have shown that the $\mathrm{IL}-1 \beta$ is a inducer of both insulin resistance and impaired pancreatic islet function (Wen et al., 2011). Despite this, findings suggest that the actions of IL-1 $\beta$ on glycemic control may be pleiotropic in nature, with IL-1 $\beta$ signaling exerting both positive and negative effects in vivo. For example, examining of IL-1 $\beta$ receptor deficiency or antagonism in in vivo animal models, as well as in clinical studies of type 2 diabetic (T2D) patients indicate that the positive actions of IL-1 $\beta$ on glycemic control (Hajmrle et al., 2016). In line with this, the acute postprandial rise in IL-1 $\beta$ production has been demonstrated to contribute to insulin secretion and is necessary for normal glycemic control (Dror et al., 2017). Our previous work highlighted the deficiency of Sirt5 in promoting IL-1 $\beta$ production by regulating PKM2 (Wang et al., 2017). Our current study confirmed macrophage-derived IL-1 $\beta$ stimulates insulin secretion in Sirt $5^{-1-}$ mice, while has no effect on insulin sensitivity. Furthermore, there is a crosstalk between macrophage and pancreatic $\beta$ cells, macrophage derived IL-1 $\beta$ and pancreatic $\beta$ cells secreted insulin synergistically regulate glucose homeostasis, which is consistent with Dror et al.'s work. The working model of this work has been shown in Fig. S7.

In addition to IL-1 $\beta$, another cytokine interferon- $\gamma$ (IFN- $\gamma$ ) has been recently reported to have a pivotal role in regulating glucose homeostasis, suggesting that immune-endocrine interactions operate at multiple levels to increase systemic insulin concentrations (Sestan et al., 2018).

In addition to pro-inflammatory cytokines influencing insulin pathway and glucose homeostasis to regulate infection, Tsai et al. recently report that InsR signaling has an impact on $T$ cell glucose metabolism and amino acid handling (Tsai et al., 2018).

In this work, we focus on the role of SIRT5 in whole body metabolism, which is important for anti-systemic bacterial infection. This work suggests that manipulating SIRT5 is an attractive option for the treatment of infection. 


\section{FOOTNOTES}

This research was financially supported by National Natural Science Foundation of China grants (81672746), National Key Research and Development Program (2018YFA0800302), National Natural Science Foundation of China grants (81872258 and 81472566).

Cuiping Zhang, Ke Wang, Zuojian Hu, Lujie Yang,Bin Wei, Shan $\mathrm{Li}$, Xue Qin, Pengyuan Yang, Hongxiu Yu declare that they have no conflict of interest declare that they have no conflict of interest. All institutional and national guidelines for the care and use of laboratory animals were followed.

Cuiping Zhang ${ }^{1,2}$, Ke Wang ${ }^{1}$, Zuojian $\mathrm{Hu}^{2}$, Lujie Yang ${ }^{1}$, Bin $\mathrm{Wei}^{3}$, Shan $\mathrm{Li}^{2}$, Xue Qin², Pengyuan Yang ${ }^{1,5 \bowtie}$, Hongxiu $\mathrm{Yu}^{1,4 凶}$

${ }^{1}$ Minhang Hospital Institutes of Biomedical Sciences, Department of Systems Biology for Medicine, School of Basic Medical Sciences, Fudan University, Shanghai 200032, China

2 Department of Clinical Laboratory, First Affiliated Hospital of Guangxi Medical University, Nanning 530021, China

${ }^{3}$ School of Life Science, Shanghai University, Shanghai 200444, China

${ }^{4}$ Minhang Hospital Institutes of Biomedical Sciences, Department of Systems Biology for Medicine, School of Basic Medical Sciences, Fudan University, Room 501, Mingdao Building, 131 Dongan Road, Shanghai 200032, China

${ }^{5}$ Minhang Hospital Institutes of Biomedical Sciences, Department of Systems Biology for Medicine, School of Basic Medical Sciences, Fudan University, Room 201, Mingdao Building, 131 Dongan Road, Shanghai 200032, China

$\checkmark$ Correspondence: pyyang@fudan.edu.cn (P. Yang), hongxiuyu@fudan.edu.cn (H. Yu)

\section{OPEN ACCESS}

This article is licensed under a Creative Commons Attribution 4.0 International License, which permits use, sharing, adaptation, distribution and reproduction in any medium or format, as long as you give appropriate credit to the original author(s) and the source, provide a link to the Creative Commons licence, and indicate if changes were made. The images or other third party material in this article are included in the article's Creative Commons licence, unless indicated otherwise in a credit line to the material. If material is not included in the article's Creative Commons licence and your intended use is not permitted by statutory regulation or exceeds the permitted use, you will need to obtain permission directly from the copyright holder. To view a copy of this licence, visit http:// creativecommons.org/licenses/by/4.0/.

Cuiping Zhang, Ke Wang and Zuojian Hu contributed equally to this work.

Electronic supplementary material The online version of this article (https://doi.org/10.1007/s13238-020-00709-7) contains supplementary material, which is available to authorized users.

\section{REFERENCES}

Dror E, Dalmas E, Meier DT, Wueest S, Thevenet J, Thienel C, Timper K, Nordmann TM, Traub S, Schulze F et al (2017) Postprandial macrophage-derived IL-1beta stimulates insulin, and both synergistically promote glucose disposal and inflammation. Nat Immunol 18:283-292

Hajmrle C, Smith N, Spigelman AF, Dai X, Senior L, Bautista A, Ferdaoussi M, MacDonald PE (2016) Interleukin-1 signaling contributes to acute islet compensation. JCl Insight 1:e86055

Hao H, Cao L, Jiang C, Che Y, Zhang S, Takahashi S, Wang G, Gonzalez FJ (2017) Farnesoid X receptor regulation of the NLRP3 inflammasome underlies cholestasis-associated sepsis. Cell Metab 25(856-867):e855

Heinonen T, Ciarlo E, Theroude C, Pelekanou A, Herderschee J, Le Roy D, Roger T (2018) Sirtuin 5 deficiency does not compromise innate immune responses to bacterial infections. Front Immunol 9:2675

Liu TF, Vachharajani VT, Yoza BK, McCall CE (2012) NAD+dependent sirtuin 1 and 6 proteins coordinate a switch from glucose to fatty acid oxidation during the acute inflammatory response. J Biol Chem 287:25758-25769

Norata GD, Caligiuri G, Chavakis T, Matarese G, Netea MG, Nicoletti A, O'Neill LA, Marelli-Berg FM (2015) The cellular and molecular basis of translational immunometabolism. Immunity 43:421-434

Schroder K, Tschopp J (2010) The inflammasomes. Cell 140:821832

Sestan M, Marinovic S, Kavazovic I, Cekinovic D, Wueest S, Turk Wensveen T, Brizic I, Jonjic S, Konrad D, Wensveen FM et al (2018) Virus-induced interferon-gamma causes insulin resistance in skeletal muscle and derails glycemic control in obesity. Immunity 49(164-177):e166

Ting JP, Willingham SB, Bergstralh DT (2008) NLRs at the intersection of cell death and immunity. Nat Rev Immunol 8:372-379

Tsai S, Clemente-Casares X, Zhou AC, Lei H, Ahn JJ, Chan YT, Choi O, Luck H, Woo M, Dunn SE et al (2018) Insulin receptormediated stimulation boosts $\mathrm{T}$ cell immunity during inflammation and infection. Cell Metab 28(922-934):e924

Tucey TM, Verma J, Harrison PF, Snelgrove SL, Lo TL, Scherer AK, Barugahare AA, Powell DR, Wheeler RT, Hickey MJ et al (2018) glucose homeostasis is important for immune cell viability during candida challenge and host survival of systemic fungal infection. Cell Metab 27(988-1006):e1007

Vachharajani VT, Liu T, Wang X, Hoth JJ, Yoza BK, McCall CE (2016) Sirtuins link inflammation and metabolism. J Immunol Res 2016:8167273

Wang F, Wang K, Xu W, Zhao S, Ye D, Wang Y, Xu Y, Zhou L, Chu Y, Zhang C et al (2017) SIRT5 desuccinylates and activates pyruvate kinase M2 to block macrophage IL-1beta production and to prevent DSS-induced colitis in mice. Cell Rep 19:2331-2344

Wen H, Gris D, Lei Y, Jha S, Zhang L, Huang MT, Brickey WJ, Ting JP (2011) Fatty acid-induced NLRP3-ASC inflammasome activation interferes with insulin signaling. Nat Immunol 12:408-415

Zhong L, D'Urso A, Toiber D, Sebastian C, Henry RE, Vadysirisack DD, Guimaraes A, Marinelli B, Wikstrom JD, Nir T et al (2010) The histone deacetylase Sirt6 regulates glucose homeostasis via Hif1alpha. Cell 140:280-293 